\title{
Desempenho das Amostras do Canal Cervical e do Fundo de Saco no Diagnóstico da Neoplasia do Colo Uterino
}

\author{
Performance of Cervical Canal and Vaginal Cul-de-sac Samples for the Diagnosis \\ of Cervical Neoplasia
}

\begin{abstract}
Luiz Carlos Zeferino, Jamira Machado Ramos Catharino, Marco Aurelio Salvino de Araujo, Luiz Carlos Borges da Silva, Silvia Regina Vedoato, Júlia Kawamura Tambascia, Edson Zangiacomi Martinez
\end{abstract}

\section{RESUMO}

Objetivos: comparar o desempenho das amostras do canal cervical e fundo de saco vaginal para o exame colpocitológico no diagnóstico da neoplasia do colo uterino.

Métodos: foram constituídos três grupos seqüenciais: grupo 1) 10.048 mulheres com amostras da ectocérvice e fundo de saco, utilizando espátula de Ayre; grupo 2) 3.847 mulheres com amostras da ectocérvice, fundo de saco e canal cervical, utilizando espátula de Ayre e escova cytobrush; grupo 3) 4.059 mulheres com amostras da ectocérvice e canal cervical, utilizando espátula de Ayre e escova cytobrush. A metodologia estatística utilizou análise de variância (ANOVA) e comparação de proporções.

Resultados: os percentuais de exames alterados dos grupos 2 (2,6\%) e 3 (2,4\%), incluindo todas as lesões escamosas e glandulares, foram significativamente maiores que no grupo 1 (2\%). Os percentuais de diagnóstico da lesão intra-epitelial escamosa de baixo grau (LIE-BG) não foram estatisticamente diferentes entre os três grupos (1,27; 1,25 e 1,07\%). Por outro lado, os percentuais de diagnóstico da lesão intra-epitelial escamosa de alto grau (LIE-AG) foram significativamente maiores nos grupos $2(0,81 \%)$ e $3(0,77 \%)$ do que no grupo 1 (0,54\%). A diferença entre os percentuais dos grupos 2 e 3 não foi estatisticamente significante.

Conclusões: a amostra do canal cervical melhora o desempenho do exame colpocitológico para o diagnóstico da lesão intra-epitelial escamosa de alto grau, ao passo que a amostra de fundo de saco não interfere significativamente nos percentuais de diagnóstico das lesões intra-epiteliais.

PALAVRAS-CHAVE: Colo do útero: lesões pré-neoplásicas. Câncer: rastreamento. Colpocitologia.

\section{Introdução}

Aproximadamente $90 \%$ das neoplasias do epitélio do colo uterino iniciam-se na sua zona Departamento de Tocoginecologia (DTG) da Faculdade de Ciências Médicas (FCM) - Área de Oncologia Ginecológica e Patologia Mamária do Centro de Atenção Integral à Saúde da Mulher (CAISM) da Universidade Estadual de Campinas (UNICAMP).

Endereço para correspondência:

Luiz Carlos Zeferino

UNICAMP/CAISM - Diretoria Executiva.

R. Alexander Fleming, 101 - Cidade Universitária "Zeferino Vaz"

13081-970 - CAMPINAS - SP

Fone: (19) 788-9402

e-mail: zeferino@caism.unicamp.br

Projeto financiado pela Fundação de Amparo à Pesquisa do Estado de São Paulo (FAPESP), Processos no ${ }^{\circ}$. 97/133221 e $97 / 13321-5$ de transformação, cujo limite interno é a junção escamocolunar. Na mulher jovem esta junção localiza-se freqüentemente na ectocérvice e após a menopausa, no interior do canal cervical ${ }^{1}$. Assim, com base nestes fatos, a melhor técnica de colheita de material cervicovaginal deveria conter amostras celulares da zona de transformação do epitélio, ultrapassando os seus limites internos.

Boon et al. ${ }^{2}$ compararam exames citológicos colhidos apenas com espátula de Ayre e com espátula mais a escova cytobrush, e observaram que a freqüência de exames citológicos positivos foi significativamente maior na técnica combinada. Vários dispositivos para colher material do canal cervical foram testados, sendo que os resultados mostraram que a utilização de técnicas que 
incluem amostragem do canal cervical apresentaram melhor desempenho ${ }^{3}$.

Pelos fatos acima expostos, a amostra do canal cervical é quase obrigatória, porém faltam informações objetivas do real papel da amostra do fundo de saco no diagnóstico citológico da neoplasia do colo uterino. Os estudos, de modo geral, não fazem referência à amostra do fundo de saco.

Pelo menos até 1988, a Organização Mundial da Saúde propunha para o exame citológico a realização rotineira da colheita de material de fundo de saco e ectocérvice ${ }^{4}$. Em 1990, a Organização Pan-Americana da Saúde propôs que fosse utilizado o cotonete para colher amostra do canal cervical, associada à amostra da ectocérvice 5 . O Ministério da Saúde do Brasil, em 1996, elaborou um projeto-piloto para o controle do câncer do colo uterino, utilizando a técnica de colheita com amostras da ectocérvice com espátula de Ayre e do canal cervical com a escova cytobrush colocadas em uma única lâmina, deixando de colher amostras do fundo de saco ${ }^{6}$.

Assim, o objetivo deste estudo foi avaliar o desempenho das amostras do canal cervical e do fundo de saco da vagina no diagnóstico citológico da neoplasia do colo uterino. Pretende-se dispor de informações que sirvam de parâmetros que orientem a definição da melhor técnica de colheita a ser preconizada.

\section{Casuistica e Métodos}

Trata-se de um estudo de série temporal préintervenção, constituído de três grupos seqüenciais em função da técnica de colheita para o exame colpocitológico, composto por mulheres atendidas no Centro de Atenção Integral à Saúde da Mulher (CAISM) da Universidade Estadual de Campinas (UNICAMP).

Grupo 1 - 10.048 mulheres que se submeteram à colheita com amostras da ectocérvice e do fundo de saco da vagina, utilizando-se a espátula de Ayre; as amostras foram colocadas em uma lâmina.

Grupo 2 - 3.847 mulheres que se submeteram à colheita com amostras da ectocérvice e fundo de saco, utilizando-se espátula de Ayre, e do canal cervical, utilizando-se escova cytobrush; as amostras da ectocérvice e fundo de saco foram colocadas numa lâmina, igual ao grupo 1, e a amostra do canal cervical em outra lâmina; ou seja, foram utilizadas duas lâminas.

Grupo 3 - 4.059 mulheres que se submeteram à colheita com amostras da ectocérvice, utilizando-se espátula de Ayre, e do canal cervical, utilizando-se escova cytobrush; as amostras foram co- locadas em apenas uma lâmina.

Foram incluidas mulheres de qualquer idade que já haviam iniciado atividade sexual e com intervalo mínimo de um ano desde o último exame colpocitológico. Foram excluídas as mulheres com exame colpocitológico anterior alterado, grávidas e aquelas atendidas no Ambulatório de Oncologia Ginecológica.

As variáveis independentes foram a técnica de colheita e a idade da mulher, e as variáveis dependentes foram o diagnóstico colpocitológico e a presença de células endocervicais no esfregaço. A idade cronológica das mulheres no momento do exame e a idade da menopausa foram consideradas como variáveis de controle para avaliar a homogeneidade entre os grupos.

Todos os exames citológicos foram realizados no mesmo laboratório, pelos mesmos citotécnicos e foram objeto de controle de qualidade, de acordo com a sistemática implantada, ou seja, revisão de pelo menos $10 \%$ dos exames citológicos com resultados normais ou com alterações benignas. Todos os exames com resultados suspeitos ou duvidosos foram examinados pelo médico citopatologista.

As fichas foram ordenadas, numeradas e digitadas em um banco de dados, utilizando-se o programa Statistical Package for Social Sciences for Personal Computer Plus (SPSS-PC). Cada mulher foi incluída apenas uma vez no estudo, prevalecendo o exame mais antigo. A identificação de multiplicidade de exames foi feita através do número de registro geral de pacientes no Serviço de Arquivo e Estatística Médica (SAME). O controle de qualidade da digitação foi realizado por amostragem (10\% do total de exames digitados) e por um programa de verificação de consistência dos dados. A metodologia estatística utilizou análise de variância (ANOVA) e teste de comparação de proporções ${ }^{7}$.

\section{Resultados}

As médias das idades cronológica e da menopausa não foram estatisticamente diferentes entre os três grupos, segundo uma análise de variância (ANOVA). As medianas da idade cronológica e da menopausa foram, respectivamente, 31 anos e 48 anos para os três grupos. Estes dados servem como indicador de homogeneidade da casuística entre os grupos (Tabelas 1 e 2).

O total de diagnósticos alterados no grupo 1 foi estatisticamente menor que o total dos grupos 2 e 3 , analisando-os em conjunto. Por outro lado, não houve diferença estatisticamente significa- 
tiva entre o total de resultados alterados entre os grupos 2 e 3 . Consideravam-se como resultados alterados os conjuntos dos seguintes diagnósticos: lesão intra-epitelial escamosa de baixo grau (LIE$\mathrm{BG})$, lesão intra-epitelial escamosa de alto grau (LIE-AG), carcinoma epidermóide invasor, adenocarcinoma e atipias celulares de significado indeterminado (Tabela 3).

Tabela 1 - Idade das mulheres quando da coleta de citologia; média \pm desvio padrão e mediana.

\begin{tabular}{lrrr}
\hline & n & Média \pm DP & Mediana \\
\hline Grupo 1 & 10.048 & $33,2 \pm 11,4$ & 31 \\
Grupo 2 & 3.847 & $33,1 \pm 11,8$ & 31 \\
Grupo 3 & 4.056 & $33,4 \pm 11,7$ & 31 \\
\hline
\end{tabular}

Grupo 1 - Colheita em ectocérvice e vagina

Grupo 2 - Colheita em ectocérvice, vagina e canal

Grupo 3 - Colheita em canal e ectocérvice

Tabela 2 - Idade da menopausa; média \pm desvio padrão e mediana.

\begin{tabular}{cccc}
\hline & $\mathbf{n}$ & Média \pm DP & Mediana \\
\hline Grupo 1 & 795 & $47,3 \pm 5,48$ & 48 \\
Grupo 2 & 309 & $47,3 \pm 6,28$ & 48 \\
Grupo 3 & 263 & $47,1 \pm 5,77$ & 48 \\
\hline
\end{tabular}

Grupo 1 - Colheita em ectocérvice e vagina

Grupo 2 - Colheita em ectocérvice, vagina e canal

Grupo 3 - Colheita em canal e ectocérvice
Tabela 3 - Diagnóstico do exame citológico nos 3 grupos.

\begin{tabular}{lrrrrrr}
\hline & \multicolumn{2}{c}{ Grupo 1 } & \multicolumn{2}{c}{ Grupo 2 } & \multicolumn{2}{c}{ Grupo 3 } \\
Diagnóstico & \multicolumn{1}{c}{$\mathbf{n}$} & \multicolumn{1}{c}{$\%$} & \multicolumn{1}{c}{$\mathbf{n}$} & \multicolumn{1}{c}{$\%$} & \multicolumn{1}{c}{$\mathbf{n}$} & \multicolumn{1}{c}{$\%$} \\
\hline Normal & 9.846 & 98,0 & 3.748 & 97,4 & 3.963 & 97,3 \\
Alterado & 202 & 2,0 & 99 & 2,6 & 96 & 2,4 \\
Total & 10.048 & 100,0 & 3.847 & 100,0 & 4.059 & 100,0
\end{tabular}

Grupo 1 contra grupo 2 e grupo $3(p=0,04)$

Grupo 2 contra grupo 3 ( $p=$ N.S.)

Os percentuais de diagnósticos de LIE-BG não foram estatisticamente diferentes entre os três grupos. Entretanto, os percentuais de diagnósticos de LIE-AG foram significativamente maiores nos grupos 2 e 3 em relação ao grupo 1. Ainda, a diferença entre os percentuais de diagnósticos de LIE-AG não foi estatisticamente diferente entre os grupos 2 e 3 (Tabela 4).

Os grupos 2 e 3 apresentaram quase quatro vezes mais esfregaços com células endocervicais em relação ao grupo 1, e esta diferença foi estatisticamente significante para todas as faixas etárias (Tabela 5). No grupo 1, o percentual de esfregaços com células endocervicais foi significativamente maior quando diagnosticada LIE-BG e LIE-AG, em comparação com o resultado normal. No grupo 2, estes percentuais foram estatisticamente semelhantes, ao passo que para o grupo 3 este percentual foi maior quando foi diagnosticado LIE-BG, em relação ao resultado normal (Figura 1).

Tabela 4 - Diagnóstico citológico segundo classificação de Bethesda.

\begin{tabular}{|c|c|c|c|c|c|c|}
\hline \multirow[b]{2}{*}{ Diagnósticos } & \multicolumn{2}{|c|}{ Grupo 1} & \multicolumn{2}{|c|}{ Grupo 2} & \multicolumn{2}{|c|}{ Grupo 3} \\
\hline & $\mathrm{n}$ & $\%$ & $\mathrm{n}$ & $\%$ & $\mathrm{n}$ & $\%$ \\
\hline Lesão de baixo grau (a) & 127 & 1,27 & 48 & 1,25 & 43 & 1,07 \\
\hline Lesão de alto grau (b) & 54 & 0,54 & 31 & 0,81 & 31 & 0,77 \\
\hline Não lesão (c) & 9.824 & 98,19 & 3.742 & 97,94 & 3.957 & 98,16 \\
\hline Total & 10.005 & 100,00 & 3.821 & 100,00 & 4.031 & 100,00 \\
\hline
\end{tabular}

(a) Taxa de detecção de LIE-AG: Grupo 1 contra grupos 2 e 3, $(p=0,04)$ Grupo 2 contra grupo $3,(p=$ N.S.)

(b) Taxa de detecção de LIE-BG: As três proporções são iguais $(p=0,60)$

(c) Excluídos também os carcinomas invasivos, adenocarcinomas e atipias celulares de significado desconhecido.

Tabela 5 - Porcentagem de esfregaços com presença de células endocervicais por faixas etárias.

\begin{tabular}{|c|c|c|c|c|c|c|c|}
\hline \multirow[b]{2}{*}{ Faixas etárias } & \multicolumn{2}{|c|}{ Grupo 1} & \multicolumn{2}{|c|}{ Grupo 2} & \multicolumn{2}{|c|}{ Grupo 3} & \multirow[b]{2}{*}{$\mathbf{p}^{*}$} \\
\hline & $\mathrm{n}$ & $\%$ & $\mathrm{n}$ & $\%$ & $\mathrm{n}$ & $\%$ & \\
\hline até 19 anos & 107 & 14,15 & 188 & 61,64 & 196 & 69,50 & $<0,01$ \\
\hline 20 a 29 anos & 673 & 17,93 & 1.027 & 72,27 & 1.140 & 75,85 & $<0,01$ \\
\hline 30 a 39 anos & 501 & 16,74 & 843 & 72,55 & 898 & 75,97 & $<0,01$ \\
\hline 40 a 49 anos & 258 & 16,66 & 426 & 72,08 & 550 & 76,50 & $<0,01$ \\
\hline 50 a 59 anos & 164 & 25,67 & 157 & 66,53 & 178 & 69,26 & $<0,01$ \\
\hline 60 anos ou + & 131 & 36,49 & 75 & 56,82 & 84 & 72,41 & $<0,01$ \\
\hline Total & 1.834 & 18,25 & 2.716 & 70,60 & 3.046 & 75,04 & $<0,01$ \\
\hline
\end{tabular}

* Grupo 1 contra grupos 2 e 3 


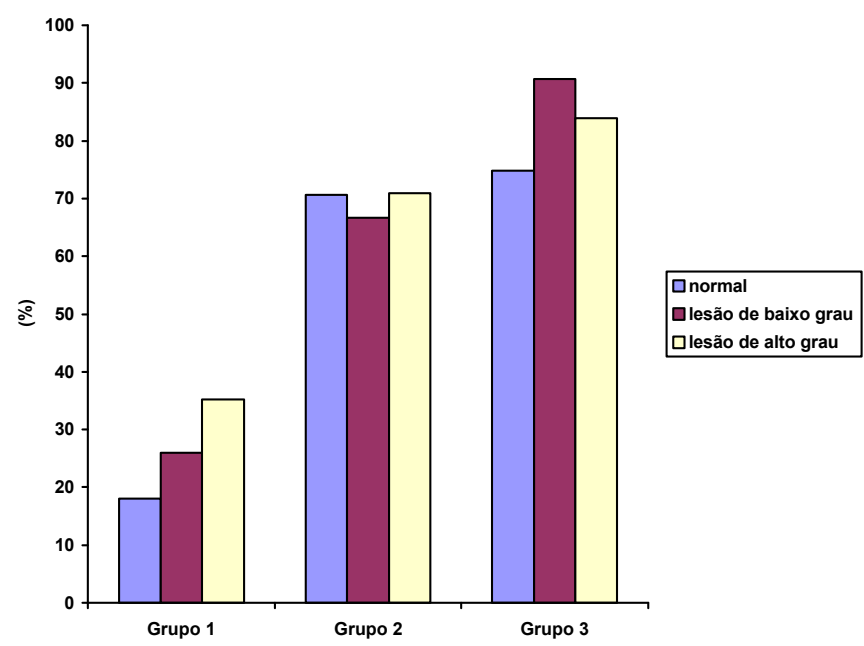

Figura 1 - Percentual de esfregaços com células endocervicais por diagnóstico, de acordo com o grupo.

\section{Discussão}

De acordo com os resultados deste estudo, a técnica de colheita do grupo 2, ou seja, amostras da ectocérvice agregadas às amostras do canal cervical e fundo de saco da vagina, e a técnica do grupo 3, com amostras da ectocérvice e canal cervical, têm melhor desempenho no diagnóstico citológico da neoplasia do colo uterino do que a técnica do grupo 1, com amostras da ectocérvice e do fundo de saco. Utilizando-se o Sistema de Bethesda, observou-se que o desempenho das técnicas dos grupos 2 e 3 é melhor para o diagnóstico das LIE-AG e o desempenho dos três grupos foi semelhante para o diagnóstico das LIE-BG.

Em estudo similar ao que corresponderia aos grupos 1 e 2, Alons-Van Kordelaar e Boon ${ }^{8}$ compararam a técnica de colheita com amostras da ectocérvice e fundo de saco e a técnica com amostras da ectocérvice, fundo de saco e canal cervical e concluíram que a técnica com amostra do canal cervical aumenta o percentual de diagnóstico das lesões cervicais escamosas. Vários trabalhos demonstraram que a associação da escova cytobrush com a espátula de Ayre tem bom desempenho para o diagnóstico citológico da neoplasia de colo uterino ${ }^{3,8-10}$.

Luzzatto e Boon ${ }^{11}$ analisaram separadamente a contribuição das amostras endocervical e ectocervical de cada exame para a detecção das lesões pré-neoplásicas do colo uterino. Concluíram que o diagnóstico de NIC 3 foi obtido em $98 \%$ das amostras endocervicais e em $62 \%$ das amostras ectocervicais, ao passo que $21 \%$ dos diagnósticos de NIC 1 e NIC 2 foram feitos exclusivamente a partir da amostra da ectocérvice. Portanto, é necessário destacar que a quase totalidade das NIC
3 foi observada na amostra endocervical, o que mostra a importância desta amostra para o diagnóstico das lesões intra-epiteliais mais graves. Os resultados daqueles autores são concordantes com nosso estudo, pois a taxa de diagnóstico das LIEAG, que inclui NIC 2 e NIC 3, foi significativamente maior para as técnicas com amostras do canal cervical.

É importante destacar que a lesão de alto grau é assim denominada porque tem maior possibilidade de evoluir para formas mais graves. Segundo estudo de meta-análise realizado por Östör ${ }^{12}, 5$ e $12 \%$, respectivamente, das NIC 2 e NIC 3 evoluiriam para câncer invasor, ao passo que apenas $1 \%$ das NIC 1 poderia ter a mesma evolução. Portanto, a amostra do canal cervical aumenta o percentual de diagnóstico das lesões com maior potencial de progredir, que se diagnosticadas e tratadas adequadamente podem causar maior redução da incidência do carcinoma invasor do colo uterino e, conseqüentemente, da morbidade e mortalidade causada por esta doença.

Por outro lado, de acordo com os resultados deste estudo, a amostra do fundo de saco não melhora significativamente a taxa de detecção da neoplasia do colo uterino. O percentual de diagnóstico de LIE-BG e LIE-AG com a técnica empregada no grupo 2, com amostra do fundo de saco, não foi estatisticamente diferente do percentual obtido com a técnica empregada no grupo 3, sem amostra do fundo de saco. O resultado foi semelhante quando se analisaram todos os diagnósticos alterados em conjunto.

Também, o percentual de esfregaços com células endocervicais foi significativamente maior em todas as faixas etárias dos grupos 2 e 3 quando comparado ao do grupo 1 . No grupo 2 , os percentuais de células endocervicais tenderam a diminuir em mulheres com 50 anos ou mais, o que pode ser decorrente das maiores dificuldades técnicas para se colher material do canal cervical em mulheres após a menopausa. O processo atrófico próprio deste período, apesar da reposição hormonal, estreita o orificio externo do colo uterino e a junção escamocolunar localiza-se freqüentemente no interior do canal. Inversamente, os percentuais de esfregaços com células endocervicais tenderam a aumentar no grupo 1, a partir dos 50 anos, quando não se utilizou amostra do canal cervical. Este resultado pode ser devido ao fato de que a quase totalidade das mulheres menopausadas incluídas neste estudo estavam em terapia de reposição hormonal, o que poderia facilitar a descamação das células endocervicais, efeito que apareceria no exame colpocitológico apenas quando não se utiliza amostra do canal cervical. 
Neste estudo, os percentuais de células endocervicais encontrados nos grupos 1,2 e 3 foram, respectivamente, 18,$2 ; 70,6$ e $75,0 \%$. Maeda et al. ${ }^{13}$ encontraram representatividade das células da junção escamocolunar em $78,4 \%$ das amostras coletadas com escovas cervicais e $15,7 \%$ apenas com espátula de Ayre, ou seja, resultados muito semelhantes.

Mauney et al. ${ }^{14}$ observaram queda progressiva do percentual de células endocervicais por faixa etária e que as taxas de resultados alterados foram maiores nos esfregaços com células endocervicais. Elias et al. ${ }^{15}$, em estudo com mulheres de 35 a 55 anos de idade, observaram que o percentual de esfregaços com células endocervicais diminui progressivamente com o aumento da faixa etária, de 89 para $83,7 \%$, e que as taxas de resultados alterados também foram maiores nos esfregaços com células endocervicais.

No grupo 1 houve apenas 18\% de esfregaços com presença de células endocervicais. Analisando a variação deste percentual em função do diagnóstico, observou-se que a proporção de esfregaços com células endocervicais foi de aproximadamente 25\% para os exames com diagnóstico de LIE-BG e de 35\% para LIE-AG. Estes resultados apenas dão mais evidência à importância da presença destas células como indicador de qualidade do esfregaço.

Coerente com estas evidências, a Organização Mundial da Saúde propõe a utilização do porcentual de esfregaços com células endocervicais como um dos indicadores para avaliação de qualidade do esfregaço colpocitológico ${ }^{4}$.

Teoricamente, a quase totalidade dos esfregaços com amostra do canal cervical deveriam apresentar células endocervicais, porém não é o que foi observado, o que pode ter duas explicações. A primeira é que a forma de utilizar a escova cytobrush não teria sido suficiente para efetivamente colher células endocervicais, uma vez que a técnica estabelecia a rotação de apenas $180^{\circ}$ da escova, ou seja, meia volta, para reduzir artefatos hemorrágicos nos esfregaços. A segunda explicação é que as células endocervicais não teriam sido identificadas na microscopia, pois um estudo mostrou que a concordância dos informes sobre estas células dentro de um mesmo laboratório foi de $80 \%{ }^{16}$. À medida que a identificação das células endocervicais se torna uma questão importante e rotineira, os percentuais de esfregaço com células endocervicais aumentam.

Portanto, é praticamente um consenso que as técnicas que incluem amostras do canal cervical são mais eficazes no diagnóstico das lesões precursoras do câncer de colo uterino, principalmente aquelas mais graves. Este fato sugere que as células colunares ou endocervicais exercem importante papel na carcinogênese do epitélio do colo uterino. O processo metaplásico a que estas células estão sujeitas, que é mais intenso na adolescência, facilitaria a incorporação e ação de agentes carcinogênicos e, como conseqüência, poderia ocorrer ou ser favorecida a ocorrência da mutagênese celular.

É necessário implementar rotineiramente a coleta de material do canal cervical para melhorar a qualidade dos esfregaços e assim reduzir os diagnósticos falso-negativos, que constituem o erro mais importante da colpocitologia. Deve-se também exigir que constem do laudo de resultado dos exames colpocitológicos se foram encontradas células endocervicais. Quando estas células não estiverem presentes no esfregaço, o ideal seria repetir a colheita de material. Se for alto o percentual de esfregaços sem células endocervicais de um determinado serviço ou profissional, é necessário rever a técnica de colheita.

Por fim, é importante considerar que a técnica com amostras da ectocérvice e do canal cervical (grupo 3) utilizou uma única lâmina, o que significa grande economia em relação à técnica com amostra tríplice, que utilizou duas lâminas (grupo 2). Quando se utilizam duas lâminas, gasta-se o dobro de corantes, lâminas e lamínulas, dobro de tempo dos técnicos para corarem os esfregaços e o dobro de tempo dos citotécnicos e citopatologistas para analisar e emitir o diagnóstico. Ainda, em serviço de alta demanda são necessários cuidados especiais para manter sempre juntas as duas lâminas do mesmo exame.

Assim, os resultados deste estudo avalizam as recomendações da Organização Pan-Americana da Saúde e do Ministério da Saúde do Brasil, que propõem amostras apenas da ectocérvice e canal cervical para o controle do câncer do colo uterino ${ }^{5,6}$. A amostra triplice em duas lâminas para o rastreamento citológico da neoplasia do colo uterino pode ser abandonada.

Concluindo, a amostra do canal cervical aumenta a taxa de diagnóstico de lesão intraepitelial escamosa de alto grau e o percentual dos esfregaços com células endocervicais, em todas as faixas etárias. Por outro lado, a subtração da amostra do fundo de saco não diminui o diagnóstico das lesões neoplásicas do colo uterino.

\section{SUMMARY}

Purpose: to compare the performance of cervical canal and vaginal cul-de-sac samples for colpocytology testing, in order 
to diagnose cervical neoplasia.

Methods: three sequential groups were constituted: group 1 - 10,048 women with ectocervix and cul-de-sac samples collected with the use of an Ayre spatula; group 2 - 3,847 women with ectocervix, cul-de-sac and cervical canal samples taken with an Ayre spatula and a cytobrush, and group 3 4,059 women with ectocervix and cervical canal samples, using an Ayre spatula and a cytobrush. ANOVA (analysis of variance) and comparison of proportions were utilized for the statistical analysis.

Results: the rates of abnormal tests in groups 2 (2.6\%) and 3 $(2.4 \%)$, including all squamous and glandular lesions, were significantly higher than in group 1 (2.0\%). The diagnosis rates of low-grade squamous intraepithelial lesion (LGSIL) were not statistically different between the three groups (1.27, 1.25 and $1.07 \%$ ). On the other hand, the diagnosis rates of high-grade squamous intraepithelial lesion (HGSIL) were statistically higher in groups 2 (0.81\%) and $3(0.77 \%)$ than in group $1(0.54 \%)$. The difference between the rates of the second and the third groups did not present any statistical significance.

Conclusions: the cervical canal sampling improves the performance of cytologic testing for the diagnosis of HGSIL, while cul-de-sac sampling does not change significantly the performance in diagnosing cervical neoplasia.

KEY WORDS: Cervical neoplasia. Cytology. Screening.

\section{Referências}

1. Burghardt E, Östör AG. Site and origin of squamous cervical cancer-a histomorphologic study. Obstet Gynecol 1983; 62:117-27.

2. Boon ME, Alons-Van Kordelaar JJ, Rietveld-Scheffers $\mathrm{PE}$. Consequences of the introduction of combined spatula and cytobrush sampling for cervical cytology: improvements in smears quality and detection rates. Acta Cytol 1986; 30:264-70.

3. Buntinx F, Brouwers M. Relation between sampling device and detection of abnormality in cervical smears: a meta-analysis of randomised and quasirandomised studies. BMJ 1996; 313:1285-90.

4. World Health Organization. Cytological screening in the control of cervical cancer: technical guidelines. Geneva: WHO; 1988.
5. Organización Panamericana de la Salud. Manual de normas y procedimientos para el control del cáncer de cuello uterino. Washington: OPAS; 1990. (Série Paltex).

6. Brasil. Ministério da Saúde. Programa Nacional de Controle do Câncer de Colo Uterino. Viva Mulher. Rio de Janeiro: Ministério da Saúde; 1996.

7. Fleiss JL. Statistical methods for rates and proportion. New York: John Wiley; 1981.

8. Alons-Van Kordelaar JJ, Boon ME. Diagnostic accuracy of squamous cervical lesions studied in spatula-cytobrush smears. Acta Cytol 1988; 32:801-4.

9. Dotters DJ, Carney CN, Droegemueller W. Nylon brush improves collection of cervical cytologic specimens. Am J Obstet Gynecol 1988; 159:814-9.

10.McCord ML, Stovall TG, Meric JL, Summitt RL, Coleman SA. Cervical cytology: a randomized comparison of four sampling methods. Am J Obstet Gynecol 1992; 166:1772-9.

11.Luzzatto R, Boon ME. Contribution of the endocervical cytobrush sample to the diagnosis of cervical lesions. Acta Cytol 1996; 40:1143-7.

12.Östör AG. Natural history of cervical intraepithelial neoplasia: a critical review. Int J Gynaecol Pathol 1993; 12:186-92.

13.Maeda MYS, Shirata NK, Longatto-Filho A, Cavaliere MJ, Santos MM, Becker CC, et al. Influência da introdução da escova cervical para colheita de material cervicovaginal no programa de rastreamento de câncer ginecológico. RBMGinecol Obstet 1993; 4:55-8.

14. Mauney M, Eide D, Sotham J. Rates of condyloma and dysplasia in Papanicolaou smears with and without endocervical cells. Diagn Cytopathol 1990; 6:18-21.

15.Elias A, Linthorst G, Bekker B, Vooijs PG. The significance of endocervical cells in the diagnosis of cervical epithelial changes. Acta Cytol 1983; 27:225-9.

16.Mitchell H. Consistency of reporting endocervical cells: an intralaboratory and interlaboratory assessment. Acta Cytol 1994; 38:310-4. 